\title{
DEM based investigation of powder packing in 3D printing of pharmaceutical tablets
}

\author{
Koyel Sen ${ }^{1}$, Tanu Mehta ${ }^{1}$, Anson W.K.Ma ${ }^{2,3}$, and Bodhisattwa Chaudhuri ${ }^{1,2,3 *}$ \\ ${ }^{1}$ Department of Pharmaceutical Sciences, University of Connecticut, Storrs, CT 06269, USA \\ ${ }^{2}$ Institute of Material Sciences, University of Connecticut, Storrs, CT 06269, USA \\ ${ }^{3}$ Department of Chemical and Biomolecular Engineering, University of Connecticut, Storrs, CT 06269, USA
}

\begin{abstract}
D printing is emerging as one of the most promising methods to manufacture Pharmaceutical dosage forms as it offers multiple advantages such as personalization of dosage forms, polypill, fabrication of complex dosage forms etc. 3D printing came into existence in 1980s but its use was extended recently to pharmaceutical industry along with the approval of first 3D printed tablet Spritam by FDA in 2015. Spritam was manufactured by Aprecia pharmaceuticals using binder jetting technology. Binder jet 3D printing involves a hopper for powder discharge and printheads for ink jetting. The properties of tablets are highly dependent upon the discharge quality of powder mixture from the hopper and jetting of the ink/binder solution from the printhead nozzle. In this study, numerical models were developed using Discrete element method (DEM) to gain better understanding of the binder jet 3D printing process. The DEM modeling of hopper discharge was performed using in-house DEM code to study the effect of raw material attributes such as powder bed packing density (i.e. particle size, particle density etc) on the printing process, especially during powder bed preparation. This DEM model was further validated experimentally, and the model demonstrated good agreement with experimental results.
\end{abstract}

\section{Introduction}

The interest in 3D printing increased significantly after FDA approval of the first 3D printed tablet Spritam by Aprecia Pharmaceuticals, New Jersey, in 2015 [1]. 3D printing including additive manufacturing in pharmaceuticals offers multiple advantages such as personalization of medicine, risk analysis, ability to manufacture complex dosage forms and low cost of development [2]. There are multiple techniques used in 3D printing such as Powder based (PB), Semi-solid extrusion (SSE), fused deposition modeling (FDM), Stereolithographic (SLA), and Selective laser sintering (SLS). Additive manufacturing involves building a threedimensional object using a CAD (computer aided design) image file. To begin with, a CAD image file is created and sent to the printer which is followed by powder discharge from the hopper onto a platform which is then spread into a thin layer by a roller and then ink/binder/Active pharmaceutical ingredient (API) solution is sprayed on top of the powder bed.

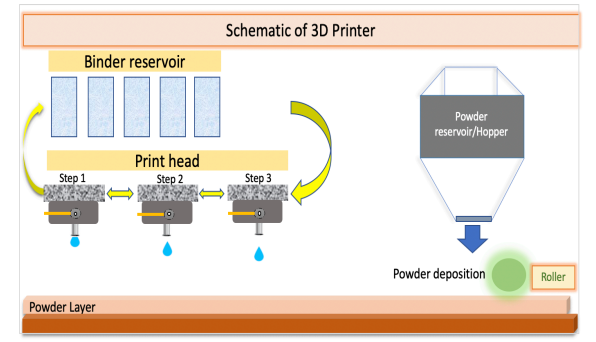

Fig. 1. Schematic of binder jetting 3D printing process

*Corresponding author: bodhi.chaudhuri@uconn.edu

A video is available at https://doi.org/10.48448/5ssz-am30
This process is repeated until the desired tablet thickness is achieved as shown in Figure 1. Once a printing cycle is over, the tablets in the powder bed are heated to $40^{\circ} \mathrm{C}$ for drying and collected carefully. The binder jetting $3 \mathrm{D}$ printing requires powder and binder liquid as the feedstock materials where the powder forms the bulk of the printed structure and binder/ink solution binds the powder together. The drug/API can be added in the printed tablets either via the ink or in the powder mixture. However, the mechanical integrity and content uniformity (in some of the cases) of the printed tablets depend on the discharge quality of the powder mixture from the installed hopper during the printing process. This study aims to develop a 3D numerical model for powder discharge from the hopper installed inside the printer using DEM and experimental validation of DEM model using powder bed packing density experiments. It is important to study the powder discharge as the powder flow from the hopper significantly affects the drug content uniformity in the final dosage form especially if drug is present in the powder mixture [3]. Powder flow also significantly affects the properties of final dosage form. DEM works by solving newtons laws of motion to calculate the trajectories of individual particles [3]. DEM mostly considers two types of particle motion $[4,5]$, collision of the particles with the boundary or with each other. There are two types of particle models that are used in DEM (i) Hard sphere model and (ii) Soft sphere model. The Numerical model used in this study was a soft sphere model [3] which includes forces as mentioned in equation 1 .

$$
\sum F_{i}=m_{i} g+F_{N}+F_{T}+F_{\text {cohesion }}
$$

Where, force on $i^{\text {th }}$ particle calculated by the sum of body/gravitational force $\left(\mathrm{m}_{\mathrm{i}} \mathrm{g}\right)$ and the inter-particle forces 
(e.g. normal force $\left(\mathrm{F}_{\mathrm{N}}\right)$, tangential force $\left(\mathrm{F}_{\mathrm{T}}\right)$ and cohesion $(\mathrm{F}$ cohesion $), \mathrm{m}_{\mathrm{i}}$ is the mass of $\mathrm{i}^{\text {th }}$ particle and $\mathrm{g}$ is the gravitational constant. The normal forces for inter-particle or particle-wall collision are modeled with "partially latching spring force model" proposed by Walton and Braun [3] and tangential forces are modeled by "incrementally slipping friction model" proposed by Walton [3]. In this study soft sphere model was applied to simulate the powder packing where the particles were modeled as soft, and elastic spheres. There are multiple factors that can affect the powder bed packing density that are studied including particle-wall friction, particleparticle friction, fill height and powder properties [3]. The DEM predicted bed packing density was then compared with bed packing density obtained using experimentation to evaluate the accuracy of DEM simulations. This DEM model can also be helpful in designing hopper, order of excipient loading for desirable powder discharge, the spatial distribution of different powder components such as excipients and, API and porosity of the powder bed to optimize the 3D printing process using a binder [3].

\section{Materials and methods}

\subsection{Numerical simulation}

\subsubsection{Geometry}

The powder discharge from the hopper was carried out in a 30.8 L wedge-shaped hopper. The geometrical dimension of the hopper and auger is given in Figure 2. The axis of rotation passes through the conical portion of the hopper. The materials used in the study were a mixture of pharmaceutical excipients listed in Table 1. The hopper and auger used in the DEM simulation were designed according to the hopper and auger installed in the 3D printer. The auger helps to prevent powder densification and generation of dead spaces.

Table 1. Composition of the blends as used in the study

\begin{tabular}{|c|c|c|c|}
\hline $\begin{array}{c}\text { Powder } \\
\text { Mixture }\end{array}$ & Composition & $(\%)$ & $\begin{array}{c}\text { DEM Particle } \\
\text { Size (mm) }\end{array}$ \\
\hline \multirow{3}{*}{$\begin{array}{c}\text { Formulation } \\
1\end{array}$} & $\begin{array}{c}\text { Lactose } \\
\text { Monohydrate }\end{array}$ & 45 & 3 \\
\cline { 2 - 4 } & MCC 101 & 45 & 6 \\
\cline { 2 - 4 } & PVP K30 & 10 & 0.6 \\
\hline \multirow{4}{*}{$\begin{array}{c}\text { Formulation } \\
2\end{array}$} & $\begin{array}{c}\text { Lactose } \\
\text { Monohydrate }\end{array}$ & 45 & 3 \\
\cline { 2 - 4 } & $\begin{array}{c}\text { Di Cal Phosphate } \\
\text { Dihydrate }\end{array}$ & 45 & 1.5 \\
\cline { 2 - 4 } & PVP K30 & 10 & 0.6 \\
\hline \multirow{3}{*}{$\begin{array}{c}\text { Formulation } \\
3\end{array}$} & $\begin{array}{c}\text { Lactose } \\
\text { Monohydrate }\end{array}$ & 45 & 3 \\
\cline { 2 - 4 } & $\begin{array}{c}\text { Di Cal Phosphate } \\
\text { Anhydrate }\end{array}$ & 45 & 1.5 \\
\cline { 2 - 4 } & PVP K30 & 10 & 0.6 \\
\hline
\end{tabular}

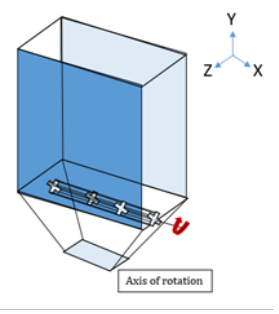

b)

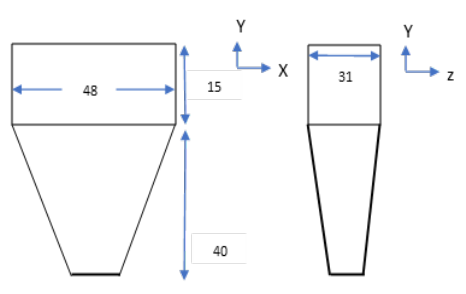

d)

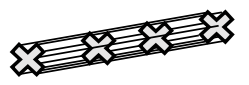

Side view

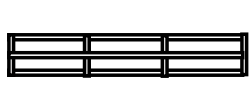

Top view

Fig. 2. a) Isometric view, b) front view, c) side view of the hopper. d) side view and, e) top view of the auger

\subsubsection{Simulation method}

The discharge behavior in a wedge-shaped hopper was simulated with the exact dimension of the lab scale hopper (Figure 2). The installed auger in the hopper rotates around the $y$-axis for discharging the powder mixture. DEM simulation and characterization generally consist of three parts: (1) Deposition of the various powder (blend) particles in the hopper; (2) discharging of the powder blends onto a Petri dish (3) Numerical characterization of the mixing by counting the number of individual particles in the granular bed. Similar to the blend formulation, a total of three different groups of particles were deposited for individual blends. The hopper was loaded with blends containing 20156, 18309, and 17869 particles representing formulation 1,2 , and 3 respectively. Table 2 shows the simulation parameters used in the DEM model. The prediction of the numerical model was verified by the bed packing density results obtained from the experiments.

Table 2. Simulation parameters used in the DEM model

\begin{tabular}{|c|c|}
\hline Simulation parameters & Values \\
\hline Coefficient of restitution (particle/wall) & 0.2 \\
\hline Coefficient of restitution (particle/particle) & 0.2 \\
\hline Frictional coefficient (particle/wall) & 0.5 \\
\hline Frictional coefficient (particle/particle) & 0.5 \\
\hline Stiffness coefficient (N/m) & 600 \\
\hline Time Step (seconds) & $2.5 \mathrm{e}-06$ \\
\hline
\end{tabular}

\subsection{Experimentation}

\subsubsection{Materials}

Three formulation blends were used in this study and the blends consisted of $45 \%$ (w/w) Lactose Monohydrate, 
45\% (w/w) PVPK30 (Polyvinyl Pyrrolidone), and one water insoluble excipient. These three specific blends were selected based on their bulk density and particle size distribution for optimizing formulation development in the binder-jet 3D printing process $[7,6]$.

\subsubsection{Powder mixture}

Three formulations as mentioned in Table 1 were prepared by mixing in a lab scale V-blender for 18 minutes at 29 RPM at $40 \%$ fill volume. The mixing regimen of the study was maintained such that the gravitational forces were higher than the centrifugal forces as optimized by previous studies from our group $[4,8]$.

\subsubsection{Quantification of powder bed packing density}

Quantification of the bed packing density for the blend was a significant step in the experiment process to validate the numerical simulation. As there was no direct method to quantify the bed packing density on the printer an indirect measurement way was adopted to mimic the bed packing density in the print bed. In a printing process, the installed hopper discharges a specific amount of powder which is then spread (with minimal pressure onto the bed) as a thin layer of powder bed by the roller (installed in the printer) on the build platform. To mimic this bed formation in lab scale, the three blends were discharged from a $15^{\circ}$ Plexiglass hopper onto a petridish and a spatula was used to smoothen the surface of the powder bed formed in the petridishes without applying excess pressure. The bed packing density was calculated by dividing the total powder weight by the volume of Petridish as shown in Figure 3. The bed packing density data retrieved from this experiment was then compared with the bed packing density data from the numerical simulation for validation purposes.

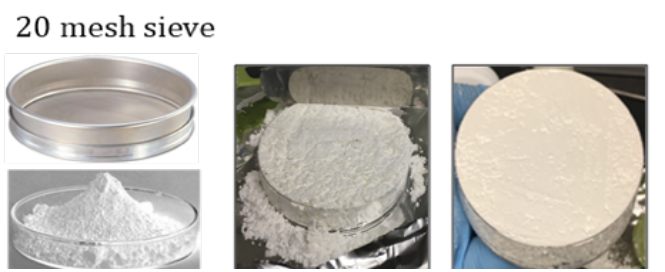

Fig. 3. Preparation of powder bed for quantifying bed packing density

\subsubsection{Hopper discharge study to estimate granular bond number for the DEM model}

It is important to consider cohesive forces between particles in the DEM model as these forces play a significant role in powder discharge [9]. The cohesive force was introduced in the simulation by incorporating a quantified force in the force model i.e., Cohesive Force Fc $=\mathrm{Kxmg}$, where $\mathrm{mg}$ is the weight of the particle. This is a short-range force (Vander Waals and/or electrostatic force) which is only applicable when the particles are in contact with each other [1]. In order to estimate cohesive forces experimentally, a dimensionless parameter known as granular bond number $(\mathrm{k})$ will be introduced which is the cohesion of the granular material compared to the weight of material. The granular bond number $(k)$ was calculated by comparing the hopper discharge rates of the blended materials as mentioned in Table 1 to the discharge rate of lactose monohydrate for which bond number was obtained from our previous studies $[4,5]$. Thus, the granular bond number for the excipients was derived from the hopper discharge experiment by comparing the discharge rate of lactose monohydrate and assigning the bond number accordingly [10]. Hopper discharge experiments (as shown in Figure $4 \mathrm{a}$ and $4 \mathrm{~b}$ ) were performed for the individual components of blends in a $15^{\circ}$ conical Plexiglas hopper at $20 \%$ relative humidity in a glovebox. The material was loaded in a closed hopper and collected in a weighing balance. All studies were recorded using a high-speed video recorder to calculate mass discharged $(\mathrm{g})$ and duration of the discharge (s). The discharge rate was calculated (Table 3 ) by dividing the mass discharged by the duration of discharge $(\mathrm{g} / \mathrm{s})$. Later on, the bond number was assigned to individual particles based on the discharge rate [9].

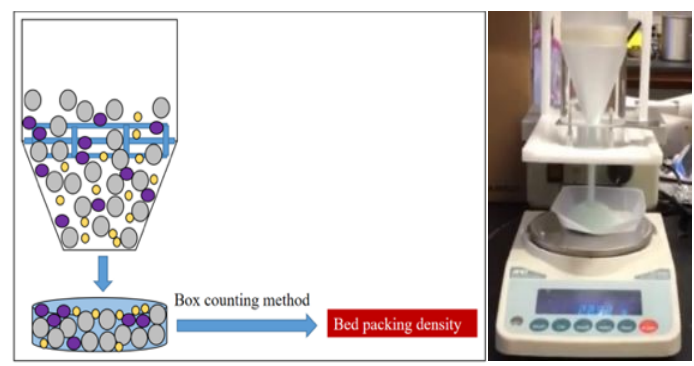

Fig. 4. a) Schematic of the hopper discharge to calculate the bed packing density for the deposited powder, b) Experimental setup for hopper discharge for bond number calculation

In this study, three different blends of formulations were used where each blend had three different types of particles that were deposited in the hopper prior to discharge. The particle sizes were simulated in the range of $3-15 \mathrm{~mm}$, which is a larger size than the actual particle in the study in order to reduce the simulation time and develop less computationally intensive DEM simulation. Although, the ratios of the particle diameter in the three participating groups for each blend used in the study were kept constant both in the experiment and simulations. The simulations were performed by depositing and discharging three different blends in a bed to determine the powder bed packing density

Table 3. Calculated bond number for individual pharmaceutical powders used in the study

\begin{tabular}{|c|c|c|c|c|c|}
\hline Formulation & $\begin{array}{c}\text { Lactose } \\
\text { Mono- } \\
\text { hydrate }\end{array}$ & $\begin{array}{c}\text { PVP } \\
\text { K30 }\end{array}$ & MCC & $\begin{array}{c}\text { Di- } \\
\text { Calcium } \\
\text { phosphate } \\
\text { Dihydrate }\end{array}$ & $\begin{array}{c}\text { Di- } \\
\text { Calcium } \\
\text { phosphate } \\
\text { Anhydrat } \\
\text { e }\end{array}$ \\
\hline 1 & 1034 & 16395 & 652 & - & - \\
\hline 2 & 1034 & 16395 & - & 36 & - \\
\hline 3 & 1034 & 16395 & - & - & 35 \\
\hline $\mathrm{k}$ & 27 & 30 & 77 & 200 & 200 \\
\hline
\end{tabular}




\section{Results and discussion}

\subsection{DEM simulations}

DEM parameters are introduced in the model and simulations were performed to study hopper discharge as shown in Figure 5 for different time intervals. Particle concentration was calculated by the "box-counting" method [11] (Figure 6a and 6b), where the petri dish was divided into small cubic domains, and the number of particles of each species were counted in each domain. The packing density was estimated using the number of particles of different types. In order to avoid spurious results, any cubic domain containing less than eight particles was eliminated from the calculation [12].

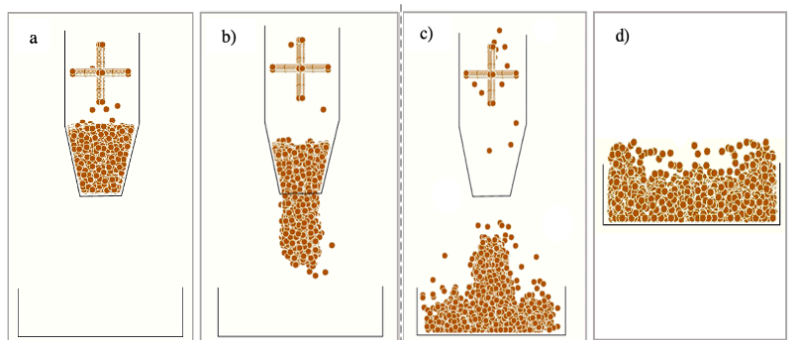

Fig. 5. Simulation snapshots showing hopper discharge in a petridish (side view), a) at time $\mathrm{t}=0 \mathrm{~s}, \mathrm{~b}$ ) at $\mathrm{t}=3 \mathrm{~s}$ and $\mathrm{c}$ ) at $t=5 \mathrm{~s}, \mathrm{~d}$ ) snapshot of the particle packing at the end of the simulation a)

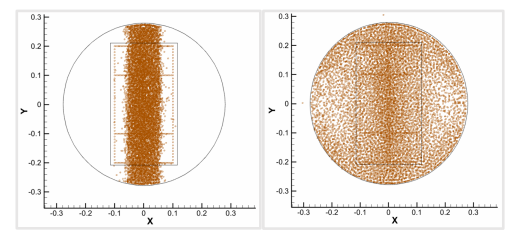

c)

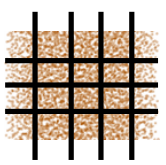

Fig. 6. a), b) Simulation snapshots at the begining and end of the powder discharge in a pertidish (top view)

c) $2 \mathrm{D}$ representation of the discretization of the simulation scheme

\subsubsection{Comparison of simulation and experiments}

To evaluate the accuracy of DEM model predictions, the mean packing density from the simulation was compared to the same from the experiments.

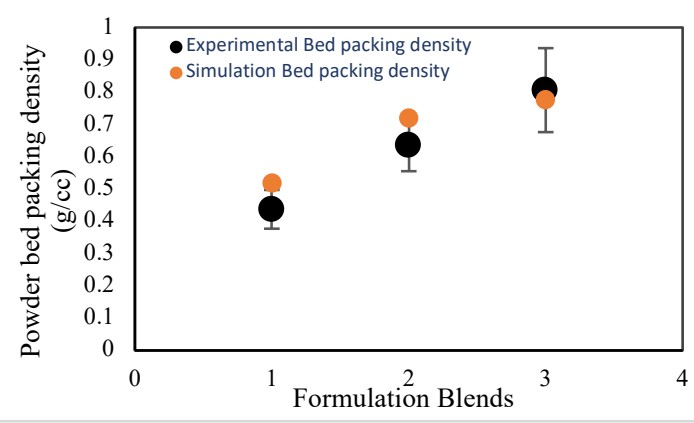

Fig. 7. Graph showing comparison of simulation and experimental data
Experimental observation showed a similar trend to the simulation (Figure 7) with higher standard deviation for higher bed packing density.

\section{Conclusion}

Understanding powder discharge from the hopper in 3D printing is significantly important to ensure the quality of the final formulation and also to develop an optimized and economical formulation development process. DEM was used to investigate the powder bed packing density for the blend of cohesive particles in a wedge-shaped hopper. It has been observed that formulation 1 due to lower bulk density provides lower bed packing density both in experiment and simulation. The powder discharge data from the simulation provided a good qualitative agreement with the experimental data. Thus, the developed DEM based predictive model can provide an understanding on the impact of raw material attributes of specific excipients on the powder bed packing density. Additionally, the DEM model can also help in formulation selection for 3D printed tablets using binderjet $3 \mathrm{D}$ printing process.

\section{References}

[1] L.K. Prasad, H. Smyth, Drug Dev. Ind. Pharm. 42, 1019-1031 (2016)

[2] S.A. Khaled, J.C. Burley, M.R. Alexander, C.J. Roberts, Int. J. Pharm. 461, 105-111 (2014)

[3] A. Anand, J.S. Curtis, C.R. Wassgren, B.C. Hancock, W.R. Ketterhagen, Chem. Eng. Sci. 64, 5268-5275 (2009)

[4] R. Mukherjee, C. Mao, S. Chattoraj, B. Chaudhuri, Int. J. Pharm. 536, 301-309 (2018)

[5] L. Vu-Quoc, X. Zhang, O.R. Walton, Comput. Methods Appl. Mech. Eng. 187, 483-528 (2000)

[6] S. Chang, A. W. K. Ma, J. of Pharm. Sci. 109, 30543063 (2020)

[7] K. Sen, A Mechanistic Understanding of Binder-jet Based 3D Printing Process ( $\mathrm{PhD}$ thesis, University of Connecticut) (2020)

[8] R. Mukherjee, K. Sen, L. Fontana, C. Mao, B. Chaudhuri, J. Pharm. Sci. 108, 223-233 (2019)

[9] B. Chaudhuri, A. Mehrotra, F.J. Muzzio, M.S. Tomassone, Powder Tech. 165, 105 -114 (2006)

[10] P.E. Arratia, N.H. Duong, F.J. Muzzio, P. Godbole, A. Lange, S. Reynolds, Powder Tech. 161, 202-208 (2006)

[11] K. Sen, N. Velez, C. Anderson, J.K. Drennen, A.S. Zidan, B. Chaudhuri, Int. J. Pharm. 578, 119131119131 (2020)

[12] P.E. Arratia, N. hang Duong, F.J. Muzzio, P. Godbole, S. Reynolds, Powder Tech. 164, 50-57 (2006) 